\section{Influences of Season and Cutting Week within a Propagation Cycle on Rooting of 'Stained Glass' Coleus Shoot Tip Cuttings Are Not Overcome by Rooting Compound Treatment}

\author{
Brigitte D. Crawford, John M. Dole ${ }^{1}$, and Ben A. Bergmann
}

ADDITIONAL INDEX wORDs. daylength, floriculture, greenhouse production, Plectranthus, Solenostemon scutellarioides, stock plants

SUMMARY. Influence of season of the year, cutting week within a propagation cycle (number of weeks from which a stock plant has been harvested), stock plant age, and rooting compound on postpropagation cutting quality, and adventitious rooting was examined for 'Stained Glass' coleus (Solenostemon scutellarioides). Cuttings were of higher quality and produced more robust root systems when a propagation cycle started in summer vs. fall or spring even when cuttings were harvested from stock plants of the same age. Cutting week within a propagation cycle significantly influenced postpropagation cutting quality and rooting when cuttings were harvested over many weeks from the same stock plants and when cuttings were harvested for three propagation events using stock plants of different ages. When cuttings were harvested on the same days from stock plants of three distinct ages, cuttings harvested in the first week were larger with greater root weights but had more yellowed leaves and lower quality ratings compared with the two subsequent cutting weeks, but stock plant age had no effect on any observed parameter.

Treatment with rooting compound did not overcome the significant influences of season and cutting week within a propagation cycle whether rooting was carried out in a greenhouse or growth chamber. Shoot and root fresh and dry weights were positively correlated with both daylength and midday instantaneous light of the stock plant environment.

$\mathrm{P}$ roduction of rooted cuttings is affected by factors such as stock plant health and age, harvesting methods, cutting treatment (e.g., storage temperature, hormone application), and environmental conditions under which stock plants are grown and cuttings are rooted. Stock plants are managed to maximize the quantity and quality of cuttings for rooting by starting with juvenile or rejuvenated source material, optimizing physiological status of the stock plant through environment manipulation, and harvesting propagules from preferred parts of the stock plants only during certain seasons (Hartmann et al., 2002).

Age of a stock plant from which cuttings are taken can influence how

\footnotetext{
Department of Horticultural Science, North Carolina State University, Raleigh, NC 27695

We acknowledge the assistance of the Floriculture Research Alliance's $P^{3}$ Research Group, NCSU statisticians, floriculture research group's technicians, graduate students, and student workers, and the NCSU Department of Horticultural Science. We especially want to thank James Altland, USDA-ARS, Application Technology Research Unit, Ohio Agricultural Research and Development Center, for conducting the leaf tissue nutrient analysis.

${ }^{1}$ Corresponding author. E-mail: jmdole@ncsu.edu.
}

doi: 10.21273/HORTTECH03464-16 readily cuttings root. Because cuttings taken from stock plants that are ontogenetically younger typically root more readily than those taken from older plants, it is advantageous for cutting producers to use stock plants in a juvenile phase. Cuttings from stock plants of suboptimal ontogenetic age can be slow rooting, have a poor rooting percentage, and result in reduced branching (Gibson, 2006).

Rooting compounds are applied to shoot cuttings to economically root cuttings of many species and cultivars. In some cases a rooting compound can be used to accelerate root initiation and to increase root number, uniformity, and quality (Dole and Wilkins, 2005). Coleus is a fast-rooting species that typically does not require rooting compound for adequate rooting. Because postrooting plant vigor is known to vary among coleus cultivars (Gibson, 2006), rooting compound may be useful to improve propagation success in cultivars with suboptimal rooting due to the influences of season of the year, cutting week within a propagation cycle (number of weeks from which a stock plant has been harvested) from the same stock plants, or stock plant age.

This study had two main objectives. The first was to determine if cutting quality and rooting success of 'Stained Glass' coleus are influenced by season, cutting week within a propagation cycle, and stock plant age. The second objective was to determine if treating 'Stained Glass' coleus cuttings with rooting compound improves rooting and rooted cutting quality when they are suppressed due to the effects of season, cutting week, or stock plant age.

\section{Materials and methods}

Plant Material. Initial 'Stained Glass' coleus stock plants were established from rooted cuttings received from a commercial supplier. Four sets of stock plants to provide experimental cuttings were established from rooted cuttings harvested from the initial stock plants. All initial and subsequent stock plants were grown under the same cultural conditions. They were grown in black plastic pots with a rim diameter of $20 \mathrm{~cm}$, a base diameter of $15 \mathrm{~cm}$, and a depth of $14 \mathrm{~cm}$. Pots were filled with peat-based soilless substrate (Fafard P3; Conrad Fafard, Agawam, MA) and plants maintained in a glass-glazed greenhouse with air temperature set at $24 / 18{ }^{\circ} \mathrm{C}$ day/ night. Shadecloth (Revolux XLS 15 Fire Retardant $50 \%$ shadecloth; Ludvig Svensson, Kinna, Sweden) covered the growing area near glass height during the middle of the day from late spring to mid fall to reduce

\begin{tabular}{llll}
\hline $\begin{array}{l}\text { Units } \\
\text { To convert U.S. to SI, } \\
\text { multiply by }\end{array}$ & U.S. unit & SI unit & $\begin{array}{l}\text { To convert SI to U.S., } \\
\text { multiply by }\end{array}$ \\
\hline 2.54 & inch(es) & $\mathrm{cm}$ & 0.3937 \\
25.4 & inch $(\mathrm{es})$ & $\mathrm{mm}$ & 0.0394 \\
0.4536 & $\mathrm{lb}$ & $\mathrm{kg}$ & 2.2046 \\
28.3495 & $\mathrm{Oz}$ & $\mathrm{g}$ & 0.0353 \\
1 & $\mathrm{ppm}$ & $\mathrm{mg} \cdot \mathrm{L}^{-1}$ & 1 \\
$\left({ }^{\circ} \mathrm{F}-32\right) \div 1.8$ & ${ }^{\circ} \mathrm{F}$ & ${ }^{\circ} \mathrm{C}$ & $\left({ }^{\circ} \mathrm{C} \times 1.8\right)+32$
\end{tabular}


greenhouse temperatures. Stock plants were fertigated via drip irrigation with $200 \mathrm{mg} \cdot \mathrm{L}^{-1}$ nitrogen $(\mathrm{N})$ from a $20 \mathrm{~N}-4.4 \mathrm{P}-16.6 \mathrm{~K}$ water-soluble fertilizer (Peters Professional; Scotts-Sierra Horticultural Products, Marysville, $\mathrm{OH})$. Liquid flowable limestone (Cleary Limestone F; Cleary Chemical, Dayton, NJ) was used to increase substrate $\mathrm{pH}$ when necessary as indicated by biweekly, substrate pour-through, $\mathrm{pH}$ testing.

Rooted cuttings to establish the first set of experimental stock plants were transplanted to the greenhouse on 23 July 2010 to be ready to begin greenhouse rooting trials in fall (12 Nov.). The two subsequent sets of stock plant were started 4 months (27 Nov. 2010) and 6 months (4 Feb. 2011) after the first set for greenhouse rooting trials starting in spring (18 Mar.) and summer (26 May). The fourth set of stock plants was established after the first year of greenhouse rooting trials (9 Oct. 2011) to conduct growth chamber rooting trials starting on 29 Jan. As a sun-type cultivar, Stained Glass coleus is not prone to flower, and cuttings were taken with sufficient frequency to avoid stock plant flowering.

RoOTING TRIALs. Shoot tip cuttings were harvested from stock plant foliage canopies for all rooting trials, and cuttings were prepared so that two or three nodes with leaves and one node at the base of the cutting with its leaf removed remained. For greenhouse rooting trials, first cutting harvest was 16 weeks after stock plants were transplanted, and subsequent cutting harvests were about every 2 weeks thereafter. Seventeen, eight, and three cutting weeks comprised the greenhouse propagation cycles starting in fall, spring, and summer, respectively (Table 1). For growth chamber rooting trials, first cutting harvest was in midwinter, 11 weeks after stock plants were transplanted, and three subsequent cutting harvests were made about every 4 weeks thereafter.

Forty shoot tip cuttings were harvested from stock plants for every rooting trial. The 40 cuttings were sorted based on stem caliper then separated into two groups of 20 , each including a similar range of cutting sizes. One group was treated with rooting compound by dipping the bottom $0.6 \mathrm{~cm}$ of stem into the

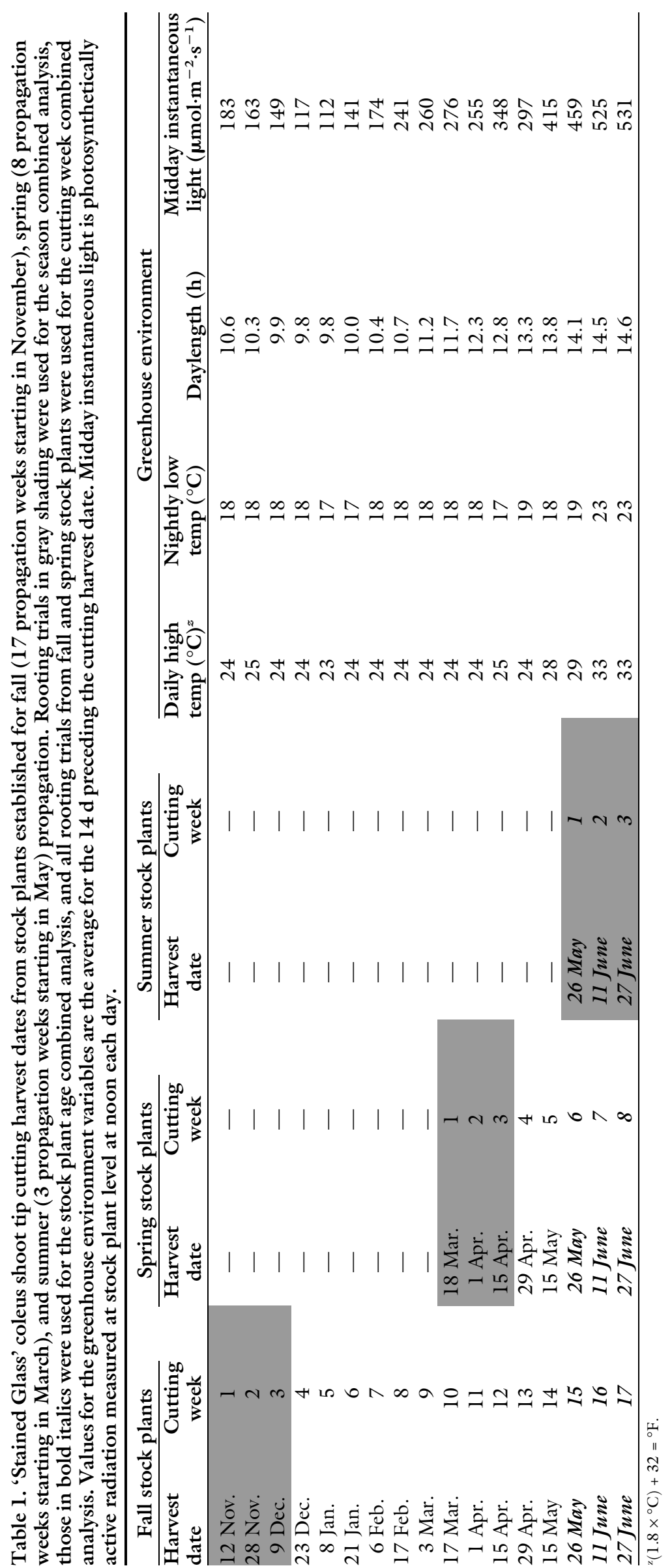


powder while leaving the other group untreated. Cuttings in greenhouse rooting trials were treated with $0.20 \%$ l-naphthaleneacetamide + $4.04 \%$ thiram (Rootone F; Gro Tec, Madison, GA), and cuttings in growth chamber rooting trials were treated with $0.1 \%$ indole-3-butyric acid (Hormodin 1; OHP, Mainland, PA). The 20 shoots within each rooting compound treatment were divided such that there were five experimental units with four cuttings each.

Cuttings were inserted into bedding plant flats with $1-1 / 2 \times 1-1 / 2 \times$ $2-1 / 8$-inch individual cells containing peat-based, soilless substrate (Fafard P4; Conrad Fafard). Environmental conditions for greenhouse rooting trials were the same for stock plants with the addition of misting for $6 \mathrm{~s}$ every $30 \mathrm{~min}$. Environmental conditions for growth chamber rooting trials were constant $21{ }^{\circ} \mathrm{C}$ and $12 \mathrm{~h}$ per day of $255 \mu \mathrm{mol} \cdot \mathrm{m}^{-2} \cdot \mathrm{s}^{-1}$ photosynthetically active radiation provided by cool white fluorescent lights. Cell packs were arranged in single rows such that the substrate surface was $15 \mathrm{~cm}$ from bulbs. Ambient high humidity was maintained by wetting the chamber floor daily, and cuttings were hand misted daily until turgidity was maintained without misting and as needed thereafter to keep substrate moist.

Observations of cutting quality and rooting success were made $14 \mathrm{~d}$ after placing cuttings into the rooting environment. Traits related to cutting health included number of yellowed/ necrotic leaves, subjective shoot quality rated on a $1-5$ scale $(1=76 \%$ to $100 \%$ damage; $2=51 \%$ to $75 \%$ damage; $3=26 \%$ to $50 \%$ damage; $4=1 \%$ to $25 \%$ damage; $5=$ no damage exhibited as chlorosis, necrosis, or wilting), shoot fresh weight, and shoot dry weight. Traits related to rooting success included objective root quality rated on a $1-5$ scale $(1=$ no roots; $2=1-5$ roots less than $2.5 \mathrm{~cm}$; $3=1-5$ roots at least $2.5 \mathrm{~cm}$, or $6-10$ roots less than $2.5 \mathrm{~cm} ; 4=6-10$ roots at least $2.5 \mathrm{~cm}$, or $10+$ roots less than $2.5 \mathrm{~cm} ; 5=10+$ roots $2.5 \mathrm{~cm}$ or longer), root fresh weight, and root dry weight.

Five cuttings in each rooting compound treatment in each rooting trial, one selected at random from the four cuttings in each experimental unit, were used to record fresh and dry weights of shoots and roots.

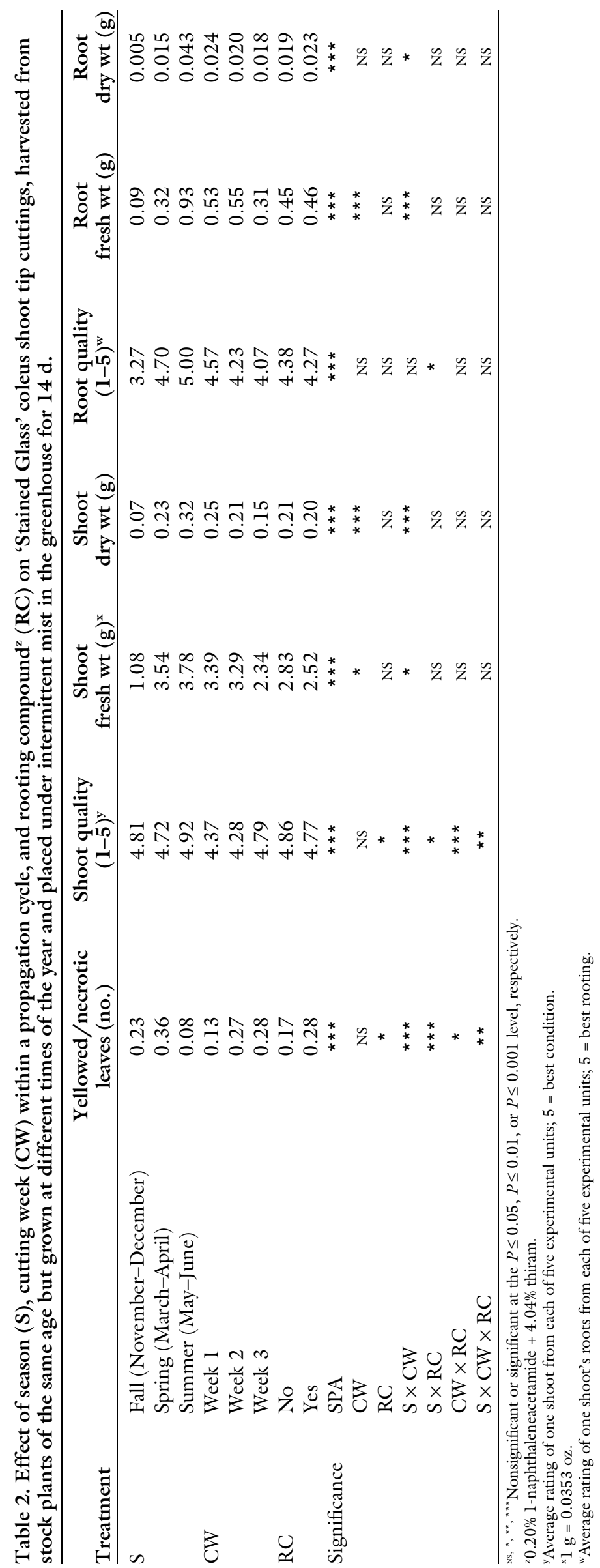

Horflechnology · October 2016 26(5) 
Substrate was rinsed from roots with water, excess water was blotted off cuttings, roots were cut from shoots, and fresh shoots and roots were weighed separately. Shoots and roots were then dried in paper envelopes in a laboratory drying oven (Precision Thelco; Thermo Fisher Scientific, Waltham, MA) at $70{ }^{\circ} \mathrm{C}$ for $48 \mathrm{~h}$, and dried shoots and roots were weighed separately.

Foliar nutrient analyses were conducted using leaves collected at the outset of each rooting trial. The fully expanded leaves removed from the lowermost node of each cutting before rooting were used to create a composite sample which was dried and ground in a sample mill (Cyclotec 1093; Foss, Hillerod, Denmark) through a $0.5-\mathrm{mm}$ screen. Nitrogen was determined with a combustion elemental analyzer (Vario Max CN; Elementar Americas, Mt. Laurel, NJ). Other macronutrient and micronutrient concentrations were determined with a spectrometer (iCAP 6000 series ICP; Thermo Fisher Scientific).

$P A R$ was measured throughout the studies each day at noon at stock plant height with a quantum light sensor (Apogee Instruments, Logan, UT) to record daily midday instantaneous light received by stock plants in the greenhouse.
Statistical analysis. Individual rooting trials were conducted as completely randomized designs with subsampling: two treatments (with or without rooting compound) and five experimental units per treatment arranged at random with four cuttings per experimental unit. Influence of season, stock plant age, and cutting week within a propagation cycle on shoot quality and rooting was accomplished through combined analyses using different subsets of the individual rooting trials (Table 1 ). Overall dependent variable means for individual rooting trials were used to examine the linear relationship between each parameter and daylength or midday instantaneous light experienced by stock plants before fall and spring greenhouse rooting trials. All statistical analyses were performed using SAS statistical software (version 9.3; SAS Institute, Cary, NC).

\section{Results}

GreENHOUSE ROOTING TRIALS: SEASON COMBINED ANALYSIS. Season had a pronounced and consistent effect on shoot quality and rooting when shoot tip cuttings were taken during 3 cutting weeks from stock plants of the same age but in different seasons (Table 2 ). All four shoot traits and all three rooting traits were highly significantly influenced by season in which rooting was done, with summer cuttings having higher shoot and root quality and shoot and root fresh and dry weights than fall and spring cuttings. Differences among the 3 cutting weeks in the season analysis were exhibited by cuttings in the first 2 cutting weeks being significantly more robust than cuttings in the third cutting week as measured by shoot fresh and dry weights and root fresh weight (Table 2). Significant but minor differences in number of yellow leaves and shoot quality were seen between cuttings that were treated with rooting compound and those that were not, and no differences were seen in shoot fresh or dry weights, rooting quality, or rooting fresh or dry weights (Table 2).

GreENHOUSE ROOTING TRIALS: STOCK PLANT AGE COMBINED ANALYSIS. Stock plant age did not have an impact on shoot quality or rooting when cuttings were taken for rooting trials from 10-, 6-, and 4-month-old stock plants on the same three dates in summer (Table 3 ). The 3 cutting weeks differed with shoot and root fresh weights and root dry weight being greater for the first cutting week than for the subsequent 2 cutting weeks (Table 3 ). Rooting compound had no impact on shoot or root quality or shoot fresh or dry weights (Table 3 ). Root fresh weight

Table 3. Effect of stock plant age (SPA), cutting week (CW) within a propagation cycle, and rooting compound ${ }^{\mathrm{z}}$ (RC) on 'Stained Glass' coleus shoot tip cuttings harvested from 10-, 6-, and 4-month-old stock plants on the same three dates (26 May, 11 June, 27 June) and placed under intermittent mist in the greenhouse for $14 \mathrm{~d}$.

\begin{tabular}{|c|c|c|c|c|c|c|c|c|}
\hline Treatment & & $\begin{array}{c}\text { Yellowed/necrotic } \\
\text { leaves (no.) }\end{array}$ & $\begin{array}{l}\text { Shoot } \\
\text { quality } \\
(1-5)^{y}\end{array}$ & $\begin{array}{c}\text { Shoot } \\
\text { fresh } \\
\text { wt }(g)^{x}\end{array}$ & $\begin{array}{c}\text { Shoot } \\
\text { dry wt (g) }\end{array}$ & $\begin{array}{c}\text { Root } \\
\text { quality }(1-5)^{w}\end{array}$ & $\begin{array}{c}\text { Root } \\
\text { fresh wt (g) }\end{array}$ & $\begin{array}{c}\text { Root } \\
\text { dry wt }(g) \\
\end{array}$ \\
\hline \multirow[t]{2}{*}{ SPA } & $10 \mathrm{mo}$. & 0.09 & 4.91 & 3.68 & 0.29 & 5.00 & 0.98 & 0.042 \\
\hline & 4 mo. & 0.08 & 4.92 & 3.43 & 0.32 & 5.00 & 0.93 & 0.043 \\
\hline $\mathrm{CW}$ & Week 1 & 0.13 & 4.87 & 4.66 & 0.38 & 5.00 & 1.08 & 0.051 \\
\hline \multirow[t]{2}{*}{$\mathrm{RC}$} & No & 0.08 & 4.92 & 3.81 & 0.32 & 5.00 & 0.90 & 0.038 \\
\hline & Yes & 0.08 & 4.83 & 3.65 & 0.30 & 5.00 & 1.01 & 0.047 \\
\hline \multirow[t]{4}{*}{ Significance } & SPA & NS & NS & NS & NS & NS & NS & NS \\
\hline & CW & $* * *$ & $* * *$ & $* * *$ & NS & NS & $* * *$ & $* * *$ \\
\hline & $\mathrm{RC}$ & NS & NS & NS & NS & NS & NS & $* *$ \\
\hline & $\mathrm{SPA} \times \mathrm{CW}$ & NS & NS & NS & * & NS & NS & NS \\
\hline
\end{tabular}

Ns, ${ }^{*},{ }^{* *},{ }^{* * *}$ Nonsignificant or significant at the $P \leq 0.05, P \leq 0.01$, or $P \leq 0.001$ level, respectively.

${ }^{2}$ Whether cuttings were treated with $0.20 \%$ l-naphthaleneacetamide $+4.04 \%$ thiram.

${ }^{y}$ Average rating of one shoot from each of five experimental units; $5=$ best condition.

${ }^{\mathrm{x}} \mathrm{l} \mathrm{g}=0.0353 \mathrm{oz}$.

"Average rating of one shoot's roots from each of five experimental units; 5 = best rooting. 
was the same whether rooting compound was used, but treated cuttings had slightly greater dry root weights (Table 3 ).

GreENHOUSE ROOTING TRIALS: CUTTING WEEK COMBINED ANALYSIS. All shoot and rooting dependent variables differed significantly among cutting weeks for the fall and spring sets of stock plants (Fig. lA-F).
Observations of yellowed/necrotic leaves followed the same but inverted pattern as those for shoot quality (data not shown). In general, cutting performance declined slightly for the 2 or 3 cutting weeks after the first cutting week, but then improved throughout the remaining cutting weeks in a propagation cycle (Fig. 1A-F). The trend of steady
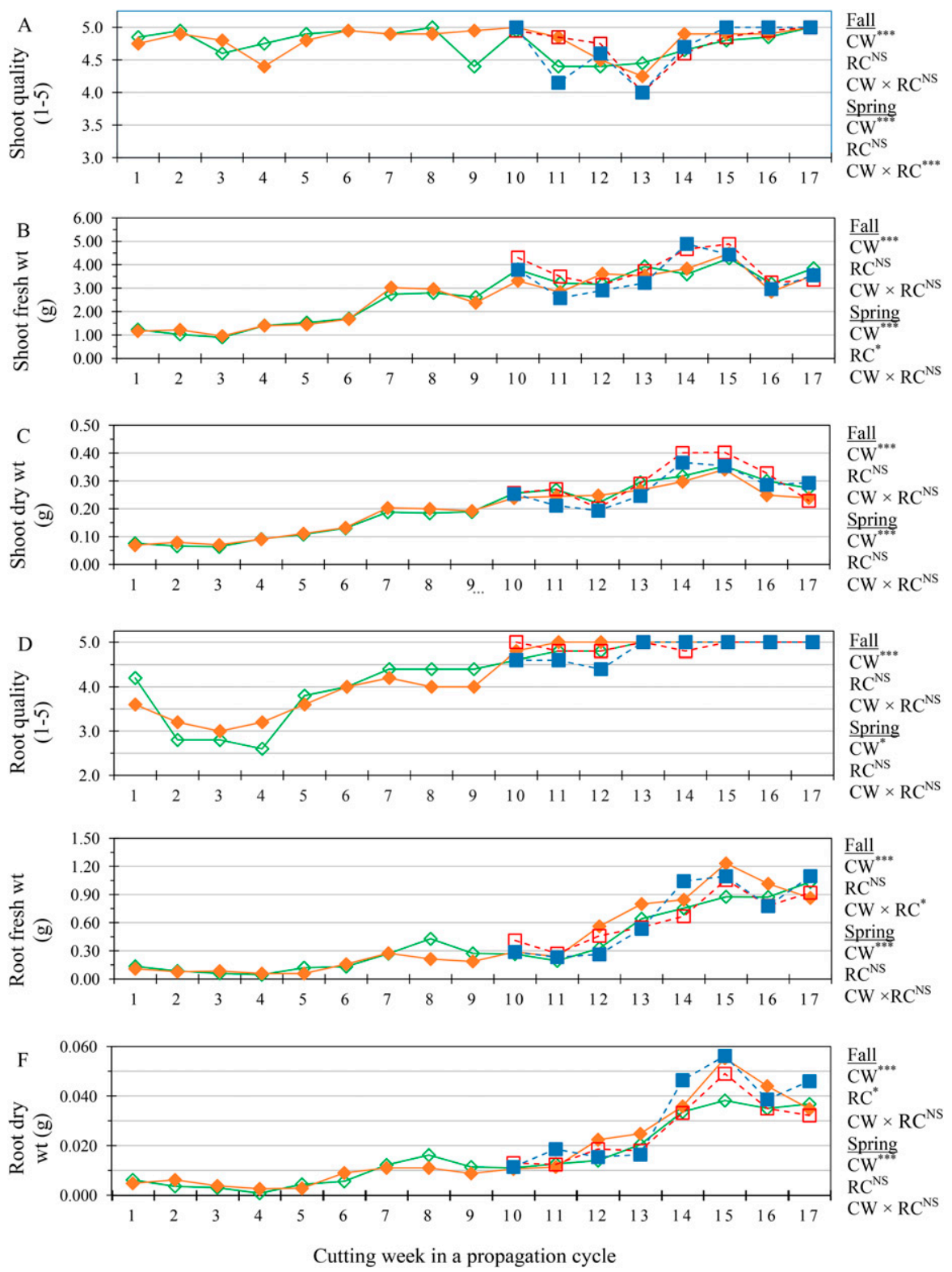

Fig. 1. Effect of cutting week (CW) and rooting compound (RC) on 'Stained Glass' coleus shoot tip cuttings, harvested starting in fall (all CWs) or spring (CWs 10-17) from separate sets of stock plants, placed under mist for $14 \mathrm{~d}$. Cuttings were taken about every 2 weeks with fall CW 1 on 12 Nov. and CW 17 on 27 June. Root and shoot fresh and dry weights are an average of weights of one shoot/root from each experimental unit $(n=5)$. Shoots were rated $1-5$ with $5=$ the best. Root qualities were rated 1-5 with 5 = the most roots. Results of two-way analyses

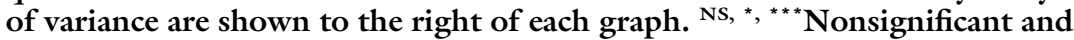
significant at $P \leq 0.05$ and 0.001 , respectively; $\diamond$ Fall no RC, $\diamond$ Fall with RC, $\square$ Spring no RC, $\square$ Spring with RC; $1 \mathrm{~g}=\mathbf{0 . 0 3 5 3} \mathrm{oz}$.

improvement in shoot and root fresh and dry weights was reversed for the last 2 cutting weeks (Fig. 1B, C, E, and $\mathrm{F}$ ), the timing of the reversal coinciding with the timing of greenhouse temperatures reaching 33/ $23{ }^{\circ} \mathrm{C}$ day/night (Table 1 ). Rooting compound had minimal effect and did not influence shoot or root quality in cuttings harvested from fall or spring stock plants (Fig. IA and D). A significant interaction between cutting week and rooting compound was observed in two cases: shoot quality in cuttings harvested from spring stock plants (Fig. 1A) and root fresh weight in cuttings harvested from fall stock plants (Fig. 1E).

GREENHOUSE ROOTING TRIALS: DAYLENGTH AND MIDDAY INSTANTANEOUS LIGHT CORRELATIONS. When rooting trials began in fall, root quality and shoot and root fresh and dry weights were positively correlated with daylength averaged over $7,14,21$, or $28 \mathrm{~d}$ before taking cuttings (Table 4 ). Similar correlations were found when rooting trials began in spring with the exception that no significant correlation was found between shoot fresh weight and daylength, and significant correlations were not as high as they were for fall rooting trials (Table 4 ). When rooting trials began in fall, no significant correlations were found between daylength and number of yellowed/necrotic leaves or shoot quality (e.g., using daylength averaged over the $14 \mathrm{~d}$ before cuttings were taken $r=0.09$ and -0.09 , respectively, with $P>0.10$ ). In nearly every case, when positive correlations were observed between daylength and a dependent variable, the correlation using the daylength the day before cutting harvest was as strong or stronger than those using daylength averaged over a greater number of days before taking cuttings (Table 4). Correlations between midday instantaneous light and root quality and shoot and root fresh and dry weights were similar in magnitude and significance as was found for daylength correlations (data not shown). There was a near absence of significant correlations between yellowed/ necrotic leaves or shoot quality and daylength in rooting trials that started in spring, as was found with the rooting trials that started in fall, yet fairly high and significant correlations between these indicators of 
Table 4. Correlations between 'Stained Glass' coleus rooted cutting dependent variables and daylength averaged over the 1 , $7,14,21$, or $28 \mathrm{~d}$ before cutting harvest day.

\begin{tabular}{|c|c|c|c|c|c|c|c|c|c|c|}
\hline \multirow[b]{2}{*}{ Days } & \multicolumn{2}{|c|}{ Shoot fresh wt } & \multicolumn{2}{|c|}{ Shoot dry wt } & \multicolumn{2}{|c|}{ Root quality } & \multicolumn{2}{|c|}{ Root fresh wt } & \multicolumn{2}{|c|}{ Root dry wt } \\
\hline & $r$ & $P$ & $r$ & $P$ & $r$ & $P$ & $r$ & $P$ & $r$ & $P$ \\
\hline & \multicolumn{10}{|c|}{ Fall stock plants } \\
\hline 7 & 0.79 & $* * *$ & 0.82 & $* * *$ & 0.73 & $* * *$ & 0.85 & $* * *$ & 0.84 & *** \\
\hline 14 & 0.77 & $* * *$ & 0.81 & $* * *$ & 0.72 & $* * *$ & 0.85 & $* * *$ & 0.84 & $* * *$ \\
\hline 21 & 0.76 & *** & 0.79 & *** & 0.70 & $* * *$ & 0.85 & $* * *$ & 0.84 & $* * *$ \\
\hline 1 & 0.12 & NS & 0.39 & $* * *$ & 0.33 & NS & 0.69 & $* * *$ & 0.71 & $* * *$ \\
\hline 7 & 0.12 & NS & 0.39 & $* * *$ & 0.33 & ** & 0.69 & $* * *$ & 0.71 & $* * *$ \\
\hline 14 & 0.12 & NS & 0.38 & $* * *$ & 0.33 & ** & 0.69 & $* * *$ & 0.71 & $* * *$ \\
\hline 21 & 0.11 & NS & 0.38 & $* * *$ & 0.33 & ** & 0.69 & $* * *$ & 0.71 & $* * *$ \\
\hline 28 & 0.11 & NS & 0.37 & $* * *$ & 0.33 & ** & 0.69 & $* * *$ & 0.71 & $* * *$ \\
\hline
\end{tabular}

${ }^{* \star},{ }^{* * *}$ Nonsignificant or significant at the $P \leq 0.01$ or $\leq 0.001$ level, respectively.

shoot health and midday instantaneous light (Table 5 ).

GrowTH CHAMBER ROOTING TRIALS: CUTTING WEEK ANALYSIS. Cutting week had a highly significant effect on shoot and root fresh and dry weights when cuttings were taken from the same greenhouse-grown stock plants on four occasions 1 month apart starting in late January and rooted in a growth chamber (Fig. 2A-D). Application of rooting hormone had a small, statistically significant, consistent, positive effect on shoot and root fresh and dry weights (Fig. 2A-D). There were no yellowed/necrotic leaves in growth chamber rooting trials, and shoot and root quality were uniformly rated as $\mathbf{5}$ (data not shown).

Nutrient analyses conducted using leaves removed from the base of cuttings at the outset of each rooting trial confirmed that cutting nutrient concentrations were consistently within the range found for high-quality coleus plants as given by Dole and Wilkins (2005).

\section{Discussion}

When 'Stained Glass' coleus was propagated by shoot tip cuttings from greenhouse-grown stock plants over multiple cutting weeks in a propagation cycle, differences among the cutting weeks were observed for number of yellowed/necrotic leaves, shoot and root quality ratings, and shoot and root fresh and dry weights in all combined analyses. Changes in cutting responses were gradual from one cutting week to the next during a long series of propagation cycles using the same stock plants (i.e., over 32 and 14 weeks for propagation cycles started

Table 5. Correlations between number of yellowed/necrotic leaves and shoot quality ratings and daylength and midday, instantaneous light averaged over the $1,7,14,21$, or $28 \mathrm{~d}$ before cutting harvest when 'Stained Glass' coleus propagation cycles started in spring and rooting took place under mist in the greenhouse for $14 \mathrm{~d}$.

\begin{tabular}{lccccc}
\hline & \multicolumn{2}{c}{ Yellowed/ necrotic leaves } & & \multicolumn{2}{c}{ Shoot quality } \\
\cline { 2 - 3 } \cline { 5 - 6 } Days & $r$ & $P$ & $r$ & $P$ \\
\hline & & Daylength & \\
1 & -0.16 & NS & & 0.20 & NS \\
7 & -0.17 & NS & & 0.20 & NS \\
14 & -0.18 & NS & 0.21 & NS \\
21 & -0.19 & NS & 0.22 & $*$ \\
28 & -0.20 & NS & 0.23 & $* * *$ \\
& & Midday, instantaneous light & & $* * *$ \\
1 & -0.46 & $* * *$ & 0.54 & $* * *$ \\
7 & -0.49 & $* * *$ & 0.55 & $* * *$ \\
14 & -0.42 & $* * *$ & 0.45 & $* * *$ \\
21 & -0.43 & $* * *$ & 0.47 & 0.42
\end{tabular}

${ }^{* *}$ Nonsignificant or significant at the $P \leq 0.05$ or $\leq 0.001$ level, respectively.

in fall and spring, respectively), and cuttings from stock plants of different ages performed similarly over multiple cutting weeks. Taken together, these observations suggest that changing seasonal environmental factors such as daylength, midday instantaneous light, and maximum and minimum temperatures during stock plant growth and/or greenhouse rooting had a greater influence on cutting performance than did stock plant age. This fact was supported by the observation that, when cuttings from stock plants of different ages were harvested on the same three dates, shoot quality and rooting parameters were similar for cuttings from all three stock plant ages, even as cutting week significantly influenced the dependent variables. Finally, that cuttings from stock plants of the same age but grown at different times of the year performed very differently underscores that season strongly influences cutting quality and rooting success in 'Stained Glass' coleus shoot tip cuttings as has been observed in other species (Roar and Andersen, 1988).

Though summer propagation resulted in cuttings with the fewest yellowed/necrotic leaves, the highest shoot and root quality, and the greatest shoot and root weights, the negative effects of seasonally high greenhouse temperatures likely explain the reversing of the trend of steadily increasing shoot and root fresh and dry weights for the last two cutting cycles for cuttings taken from fall and spring stock plants. Greenhouse daily average high and low temperatures for the 2 weeks of rooting during both of the last two rooting 

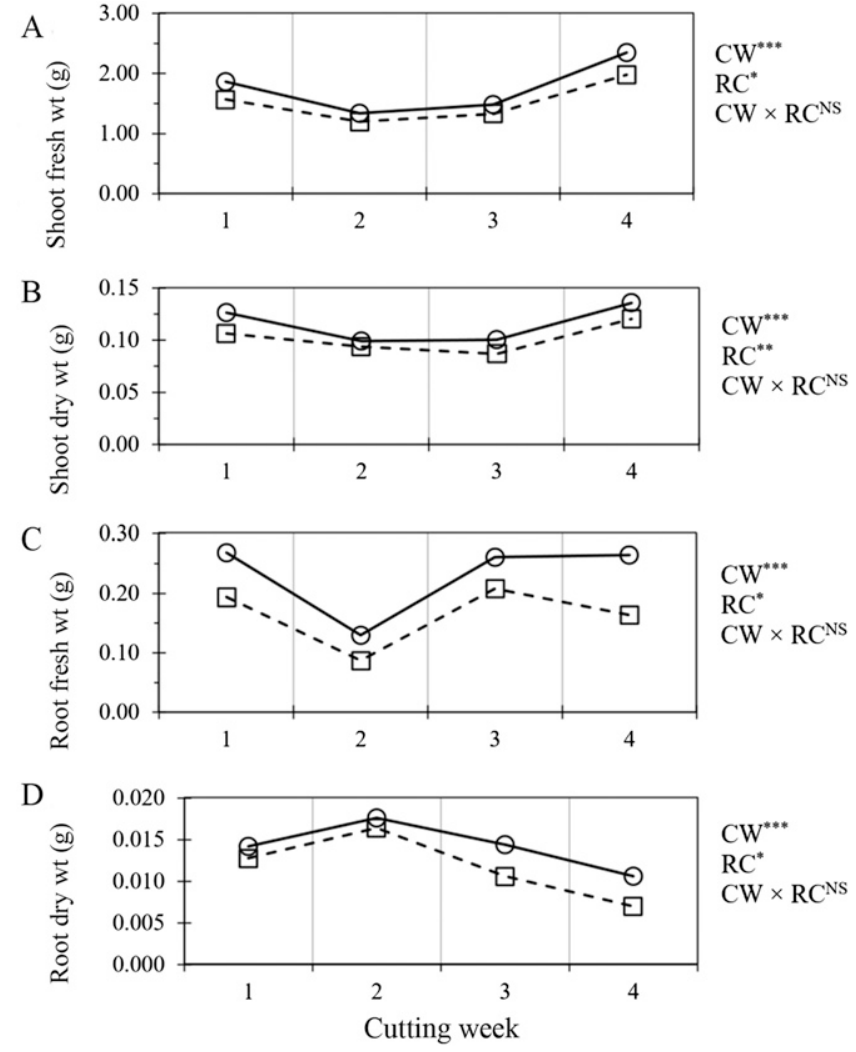

Fig. 2. Effect of cutting week (CW) and rooting compound (RC) on shoot and root fresh and dry weights of 'Stained Glass' coleus shoot tip cuttings rooted in a growth chamber for $14 \mathrm{~d}$. Cuttings were taken from the same stock plants every 4 weeks starting on 29 Jan. Weights are an average of one shoot/root from each experimental unit per RC treatment $(n=5)$. Inset in each graph are results from

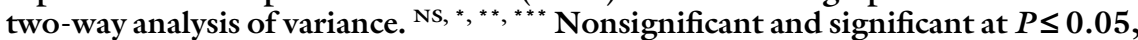
0.01 , and 0.001 , respectively; $\square$ no RC, $\bigcirc$ with $\mathrm{RC}$; $1 \mathrm{~g}=\mathbf{0 . 0 3 5 3} \mathrm{oz}$.

cycles were 33 and $23{ }^{\circ} \mathrm{C}$, respectively, well above the upper end of the optimal day/night temperature ranges for callusing $\left(29 / 21^{\circ} \mathrm{C}\right)$ and root development $\left(27 / 21{ }^{\circ} \mathrm{C}\right)$ in coleus shoot tip cuttings (Dole et al., 2006). It is likely that cuttings, though visually of high quality, were physiologically less amenable for rooting than the previous rooting cycles because they were harvested from stock plants that were growing further from the optimal production temperatures of $24 / 18{ }^{\circ} \mathrm{C}$ day/night (Dole et al., 2006). Such negative impacts of temperature have been described by Erwin (1995) in new guinea impatiens (Impatiens hawkeri) and by Erwin and Heins (1993) in geranium (Pelargonium $\times$ hortorum). One possible explanation is that cutting carbohydrate type and/or content was lower from the start when cuttings were taken from plants grown at supraoptimal temperatures and continued to be too low for best rooting when rooting was also done at supraoptimal temperatures as seen in geranium (Druege and Kadner, 2008; Rapaka et al., 2005).

This research shows that rooting success changes over the course of many cutting weeks within a propagation cycle when stock plants are grown and rooting is carried out in the greenhouse. As has been found with other coleus cultivars (Garland et al., 2010), we found that the changing daylength and midday instantaneous light were significantly, positively correlated with shoot weights and root quality and weights when propagation cycles were initiated in fall or spring and rooting was done in the greenhouse. Correlations were at least as strong when using daylength and midday instantaneous light for the day before cuttings were taken as when averages for the light variables were calculated over the previous $7,14,21$, or $28 \mathrm{~d}$. In the case of cuttings from stock plants starting in the spring, midday instantaneous light had higher and stronger correlations than did daylength with number of yellowed/necrotic leaves and shoot quality. Our findings with 'Stain Glass' coleus are in line with the findings of Currey et al. (2012) who reported that quality of rooted cuttings and their root and shoot dry weight increased dramatically with increasing photosynthetic daily light integrals during root development in six herbaceous bedding plant species.

We found that cutting week within a propagation cycle influenced shoot quality and rooting even when the variable environmental conditions of the greenhouse were replaced with highly controlled growth chamber conditions to carry out rooting. Daylength and midday instantaneous light of the stock plants' environment was increasing throughout the growth chamber rooting trials, but we did not observe consistent trends in shoot and root fresh and dry weights as we found in the greenhouse rooting trials. This suggests that both the stock plant greenhouse environment before cutting harvest and the variable greenhouse propagation environment influenced cutting performance.

Application of rooting compound did not affect postpropagation shoot quality and rooting in 'Stained Glass' coleus when shoot tip cuttings were rooted under variable greenhouse conditions. While use of rooting compound during growth chamber rooting yielded cuttings with statistically greater shoot and root weights, the absolute difference between treated and untreated cuttings was small and likely not of commercial importance. These two observations are not surprising as coleus is a species that roots rapidly, and rooting compound is not considered to be required for propagation (Dole et al., 2006). Most interesting is that rooting compound did not overcome stock plant and cutting week influences whether rooting was carried out in greenhouse or growth chamber.

\section{Literature cited}

Currey, C.J., V.A. Hutchinson, and R.G. Lopez. 2012. Growth, morphology, and quality of rooted cuttings of several herbaceous annual bedding plants are influenced by photosynthetic daily light integral during root development. HortScience 47:25-30. 
Dole, J.M., J.L. Gibson, and H.F. Wilkins. 2006. Crop-by-crop cutting propagation, p. 230-362. In: J.M. Dole and J.L. Gibson (eds.). Cutting propagation. Ball Publ., Batavia, IL.

Dole, J.M. and H.F. Wilkins. 2005. Floriculture principles and species. Pearson Prentice Hall, Upper Saddle River, NJ.

Druege, U. and R. Kadner. 2008. Response of post-storage carbohydrate levels in pelargonium cuttings to reduced air temperature during rooting and the relationship with leaf senescence and adventitious root formation. Postharvest Biol. Technol. 47:126-135.

Erwin, J. 1995. Light and temperature, p. 4l-54. In: W. Banner and M. Klopmeyer (eds.). New Guinea impatiens. Ball Publ., Batavia, IL.

Erwin, J.E. and R.D. Heins. 1993. Light and temperature, p. 55-63. In: J.W. White (ed.). Geraniums IV. Ball Publ., Geneva, IL.

Garland, K.F., S.E. Burnett, L.B. Stack, and D. Zhang. 2010. Minimum daily light integral for growing high-quality coleus. Hort Technology 20:929-933.

Gibson, J.L. 2006. Stock plant management, p. 31-38. In: J.M. Dole and J.L. Gibson (eds.). Cutting propagation. Ball Publ., Batavia, IL.

Hartmann, H.T., D.E. Kester, F.T. Davies, Jr., and R.L. Geneve. 2002. Plant propagation: Principles and practices. 7 th ed. Pearson Prentice Hall, Upper Saddle River, NJ.

Rapaka, V.J., B. Bessler, M. Schreiner, and U. Druege. 2005. Interplay between initial carbohydrate availability, current photosynthesis, and adventitious root formation in Pelargonium cuttings. Plant Sci. 168:1547-1560.

Roar, M. and A.S. Andersen. 1988. Stock plant environment and subsequent adventitious rooting, p. 214-234. In: T.D. Davis, B.E. Haissig, and N. Sankhla (eds.). Adventitious root formation in cuttings. Dioscorides Press, Portland, OR. 